\title{
ИЗУЧЕНИЕ ВЛИЯНИЯ ЗЛАКОВЫХ ХЛОПЬЕВ НА КАЧЕСТВО ХЛЕБОБУЛОЧНЫХ ИЗДЕЛИЙ
}

\author{
N.G. Batura, N.N. Tipsina
}

\section{STUDY OF THE INFLUENCE OF CEREAL FLAKES ON THE QUALITY OF BAKERY PRODUCTS}

Батура Н.Г. - асп. каф. технологий хлебопекарного, кондитерского и макаронного производств Красноярского государственного аграрного университета, технолог-менеджер ИП Суфу-дэ И.В., г. Красноярск.

E-mail: tehnolog@sufude.ru

Типсина Н.Н. - д-р техн. наук, проф. каф. технологий хлебопекарного, кондитерского и макаронного производств Красноярского государственного аграрного университета, г. Красноярск. E-mail: info@kgau.ru

Цель работы - изучение влияния крупяных хлопьев на пищевую ценность и технологические качества хлеба с применением нетрадиционного сырья. Злаковые хлопья широко распространены в кулинарных изделиях и недостаточно используются в хлебопечении. При изготовлении злаковых хлопьев сохраняются алейроновый слой и зародыш зерна. Внесение хлопьев в рецептуру хлебобулочных изделий обогащает их содержанием пищевых волокон, полезньми микроэлементами. В рамках проведенных исследований установлены оптимальные параметры внесения зерновых хлопьев в рецептуры изделий. Оптимальным количеством можно считать диапазон внесения сухих хлопьев от 10 до 20 \% к массе муки. $B$ uелях оптимизации процессов тестоведения установлены технологические параметры внесения: температура воды для замачивания 22-25 ${ }^{\circ} \mathrm{C}$ и процесс набухания не более 3 часов. Более длительное нахождение в воде хлопьев может привести к забраживанию полуфабриката. Влагоудерживающая способность зерновых хлопьев колеблется от 87 до $97 \%$. Установлено, что применение хлопьев в производстве хлебобулочных изделий повышает выход хлеба в среднем на 5-7 \%. Органолептическая оценка готовых изделий с применением хлопьев показала их высокий уро-
Batura N.G. - Post-Graduate Student, Chair of Technology of Baking, Confectionery and Macaroni Productions, Krasnoyarsk State Agrarian University, Technologist Manager, SP "Su-fu-de I.V.", Krasnoyarsk.

E-mail: tehnolog@sufude.ru

Tipsina N.N. - Dr. Techn. Sci., Prof., Chair of Technology of Baking, Confectionery and Macaroni Productions, Krasnoyarsk State Agrarian University, Krasnoyarsk.

E-mail: info@kgau.ru

вень. Введение в рещептуру хлеба зерновых хлопьев продлевает сроки свежести хлеба на 2-3 суток. Использование злаковых хлопьев в качестве хлебопекарного сырья позволяет оптимизировать существующую технологию зерновых хлебов. Технологический процесс изготовления хлебов с использованием хлопьев сокращает процесс тестоведения на 2-6 часов. Технологический процесс подготовки хлопьев к производству не предусматривает установки дополнительного оборудования и производственных площадей.

Ключевые слова: зерновой хлеб, зерновые хлопья, технология, качество.

The aim of the work is to study the influence of cereal flakes on the nutritional value and technological qualities of bread produced using nontraditional raw materials. Cereal flakes are widespread in culinary products and are unwarranted by the bakery industry. In the manufacture of cereal flakes, the aleuron layer and drain germ are preserved. The introduction of flakes in the recipe of bakery products enriches them with the content of dietary fiber, useful trace elements. Within the framework of the carried out studies, optimal parameters of inclusion cereal flakes in product formulations have been established. Optimal amounts can be considered the range of dry flakes applica- 
tion from 10-20\% of flour weight. In order to optimize the processes of dough science technological parameters of application have been established: the temperature of water for soaking is $22-25{ }^{\circ} \mathrm{C}$ and the swelling process should not exceed 3 hours. Longer flakes in the water can lead to fermentation of the semi- finished product. The moisture retention capacity of cereal flakes ranges from 87 to $97 \%$. It has been found that the use of flakes in the production of bakery products the yield of by $5-7 \%$ on average. Organoleptic evaluation of finished products using flakes showed their high level. Availability of products gives confidence in the possibility of creating constant demand for products in the population. The introduction of cereal flakes in grain bread in the recipe extends the bread freshness by 2-3 days. The use of cereal flakes as a baking raw material allows us to optimize the existing technology of grain breads. The technological process of making bread using cereals reduced the test process by 2-6 hours. The technological process of preparing cereal of production does not include the installation of additional equipment and production facilities.

Keywords: Grain bread, cereal flakes, technology, quality.

Введение. Существует мнение, что хлеб мало полезен для здоровья и вредит нашей фигуре. Встает резонный вопрос: так ли это?

Хлеб и хлебобулочные изделия являются основой рациона человека на протяжении всего его существования. Первые факты переработки зерен злаковых культур археологи находят на стоянках древнего человека. Уже тогда появлялись первые опыты изготовления продукта, напоминающего современные лепешки из расплюснутого зерна. Дальнейшее развитие техники и технологии дало нам возможность в настоящее время наслаждаться широким ассортиментом аппетитных изделий.

Сегодня нельзя отрицать тесной связи бесконтрольного употребления пшеничного хлеба и все возрастающих проблем лишнего веса. Многие в борьбе за стройную фигуру отказались от употребления хлеба в любых его исполнениях. Такой подход к формированию диеты нецелесообразен.

Хлеб и хлебобулочные изделия являются основным продуктом на столах подавляющего большинства населения. Кроме того, хлеб является стратегическим продуктом, доступным для широких масс населения. Исключить из рациона социально значимый продукт - значит создать напряжение в среде малообеспеченных граждан и спровоцировать их недовольство [1].

Совершенно неверно считать хлеб продуктом, опасным для здоровья человека. Правильно изготовленный хлеб содержит достаточное количество полезных веществ - витамины, микроэлементы, пищевые волокна, аминокислоты и пр. Чтобы повысить пищевую ценность и значимость хлеба массового производства, необходимо снизить его калорийность и насытить полезными элементами [2].

Сегодня существует множество способов изготовить хлеб и хлебобулочные изделия, обогащенные полезными веществами. Одно из направлений развития хлебопечения в этом направлении - использование в качестве сырья плющеного зерна, крупяных хлопьев [3].

Цель работы. Изучение влияния злаковых хлопьев на качество хлебобулочных изделий.

Задачи: определение влагоудерживающей способности хлопьев; выбор рациональной дозировки хлопьев в рецептурах; определение технологических параметров при изготовлении хлебобулочных изделий, экономической целесообразности применения злаковых хлопьев в хлебопечении.

Объекты и методы исследований. В качестве объектов исследования использовались хлопья овсяные по ГОСТ 21149-93, хлопья пшеничные по ГОСТ Р 50365-92, хлопья ржаные производства FAZER (Финляндия) и изготовленные из них хлебобулочные изделия.

Исследования по показателям качества проводились в лабораториях КрасГАУ и ИП Су-фудэ И.В. Изучение показателей проводилось по стандартным методикам определения показателей качества, применяемым в хлебопекарной промышленности.

Влажность готовых хлебобулочных изделий определялась по ГОСТ 21094-75 «Хлеб и хлебобулочные изделия. Методы определения влажности», зольность - по ГОСТ 27494-2016 «Мука и отруби. Методы определения зольности», ГОСТ Р 51411-99 ( ИСО 2171-93) «Зерно и продукты его переработки. Определение зольности». 
Органолептическая оценка объектов исследования проводилась по ГОСТ 5667-65 «Хлеб и хлебобулочные изделия. Правила приемки, методы отбора образцов, методы определения органолептических показателей и массы изделий».

Влагоудерживающую способность хлопьев определяли процентно-весовым методом. Для чего сухие хлопья взвешивали на весах 2-го класса точности, замачивали однократным количеством воды. Периодически отцеживали невпитавшуюся жидкость. При трехкратном повторении результатов взвешивания процентным методом определяли количество воды, способной удерживаться зерном, - таким образом были получены показатели влагоудерживающей способности злаковых хлопьев.

Выход хлеба и хлебобулочных изделий определяли по методическим указаниям, принятым в хлебопекарной промышленности и используемым на предприятиях, выпускающих хлеб и хлебобулочные изделия [4].

Результаты и их обсуждение. Для решения поставленных задач проведены исследования различных злаковых хлопьев по фризикохимическим и органолептическим показателям.

Из литературных источников известно, что витамины группы В в большей степени находятся в алейроновом слое зерна, а витамины $E$ и РP в основном содержатся в зародыше зерна. Мукомольное производство организовано таким образом, что при шлифовке зерна вместе с плодовой оболочкой снимается алейроновый слой. Зародыш зерна также удаляется при размоле.

Таким образом, мука высших сортов обладает большей калорийностью и содержит в большей степени углеводы, а полезные вещества, витамины, пищевые волокна, необходимые для полноценного питания человека, попадают в отходы мукомольного производства.

Решить проблему обеспечения населения здоровыми продуктами, богатыми микроэлементами, витаминами и другими жизненно важными компонентами, может использование в хлебопечении пищевых круп, злаковых хлопьев.

При изготовлении пищевых хлопьев сохраняется алейроновый слой зерна и зародыш, которые позволяют насытить хлебобулочные изделия пищевыми волокнами, аминокислота- ми, макро- и микроэлементами и жизненно важными витаминами группы B, E и РP. Все это богатство, данное природой зерну, утилизируется при изготовлении муки мелкого помола высшего качества.

Эфффективность использования хлопьев, кроме их полезности, обусловливается еще и технологичностью их использования. При изготовлении хлопьев зерно подвергается очистке, технологической температурной обработке. Процесс плющения зерна меняет его плотность и позволяет воде глубже и быстрее проникать внутрь зерна. Вместе с тем сохраненная клеточная структура зерна способна к набуханию и удержанию влаги внутри клеточного пространства. Таким образом, водопоглотительная и влагоудерживающая способность плющеных зерен значительно выше, чем у целого зерна и муки (рис. 1).

Количество поглощенной воды определялось методом взвешивания. Навеску хлопьев 100 г взвешивали на весах, добавляли питьевую воду С температурой $20-25{ }^{\circ} \mathrm{C}$ в количестве 100 г. Смесь хлопьев с водой выдерживали 1, 3, 5, 10, 24 часа. Периодически отцеживали, взвешивали и возвращали влагу в смесь для дальнейшего набухания. Смеси находились в условиях производственной лаборатории при температуре 22-27 ${ }^{\circ} \mathrm{C}$. Наиболее оптимальное время замачивания 3 часа, дальнейшее замачивание нецелесообразно, так как влагоудерживающая способность после 3 часов не увеличивалась, а признаки брожения начали проявляться после 12 часов нахождения смеси в лаборатории. После 12 часов набухания хлопьев появился запах брожения, кисловатый привкус. Для производственных цехов набухание хлопьев более 3 часов нерентабельно, так как занимаются дополнительные производственные площади и оборудование, для более длительного хранения смеси хлопьев и воды необходимо применять холодильное оборудование, а это также отрицательно сказывается на экономических показателях предприятия.

Для определения оптимальной рецептуры хлебобулочных изделий с применением различных хлопьев злаковых культур были проведены пробные выпечки. Замоченные хлопья дозировались в рецептуру изделий из расчета $10,15,20,30$ и 50 \% сухих хлопьев к массе му- 
ки. В рамках поставленных задач проводились органолептические и технологические оценки качества изделий. Наиболее показательными из органолептических характеристик выделены вкус и крошливость, так как они являются опре- деляющими при выборе изделий покупателями. Выход хлебобулочных изделий с использованием хлопьев сравнивался с выходом хлебобулочных изделий по стандартной технологии из муки высшего сорта.

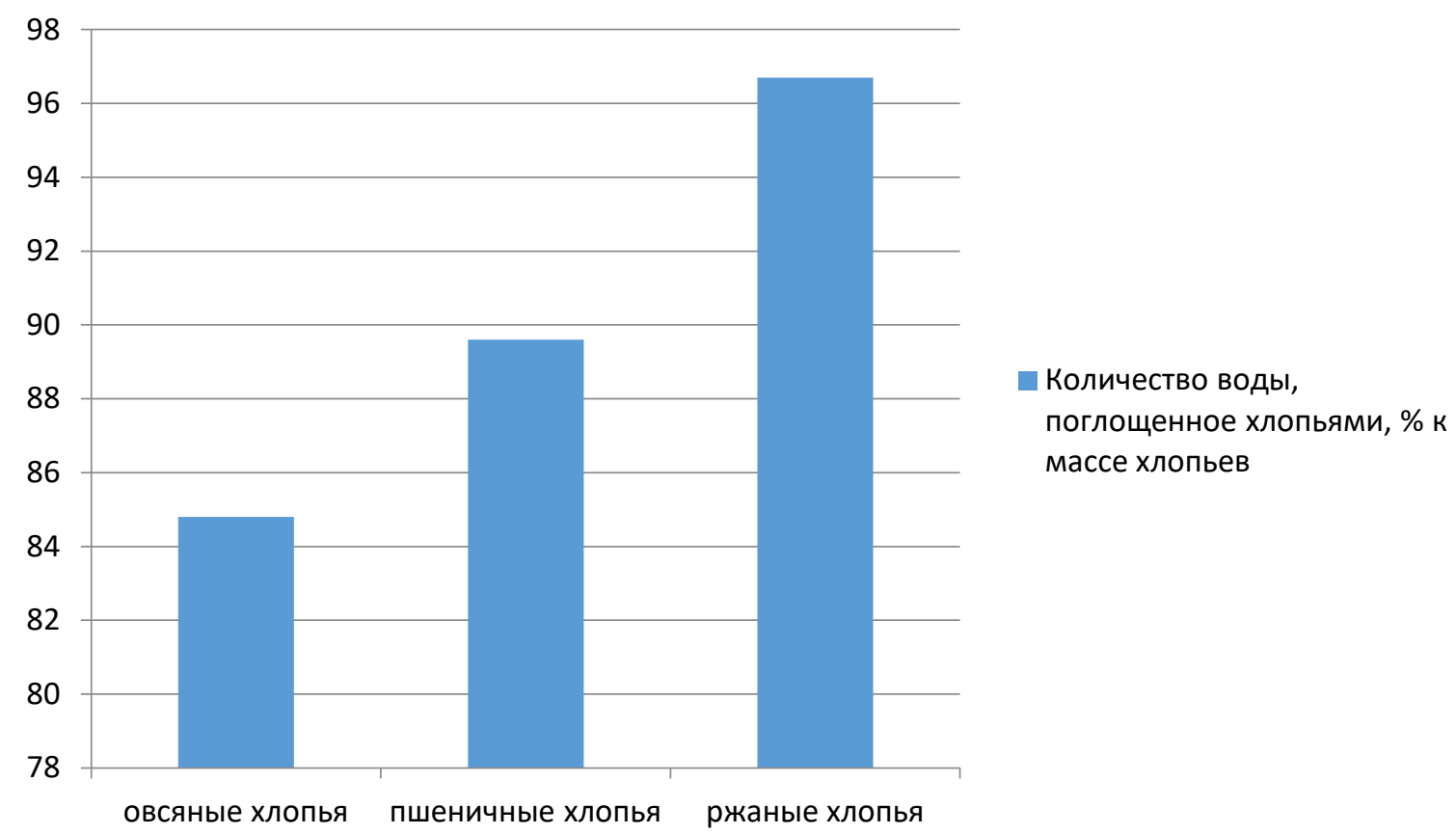

Рис. 1. Количество воды, поглощенное хлопьями, \% к массе хлопьев

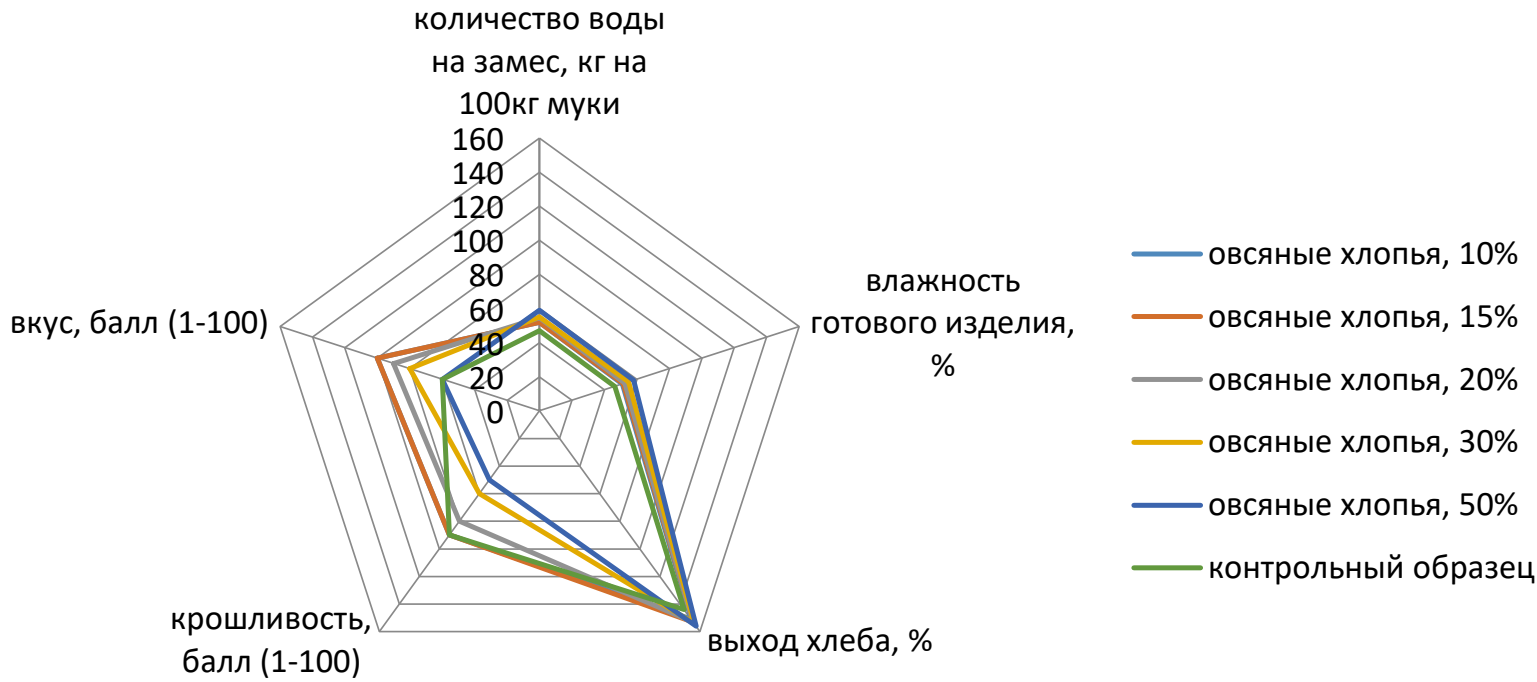

Pис. 2. Влияние дозировки овсяных хлопьев на качество хлеба 


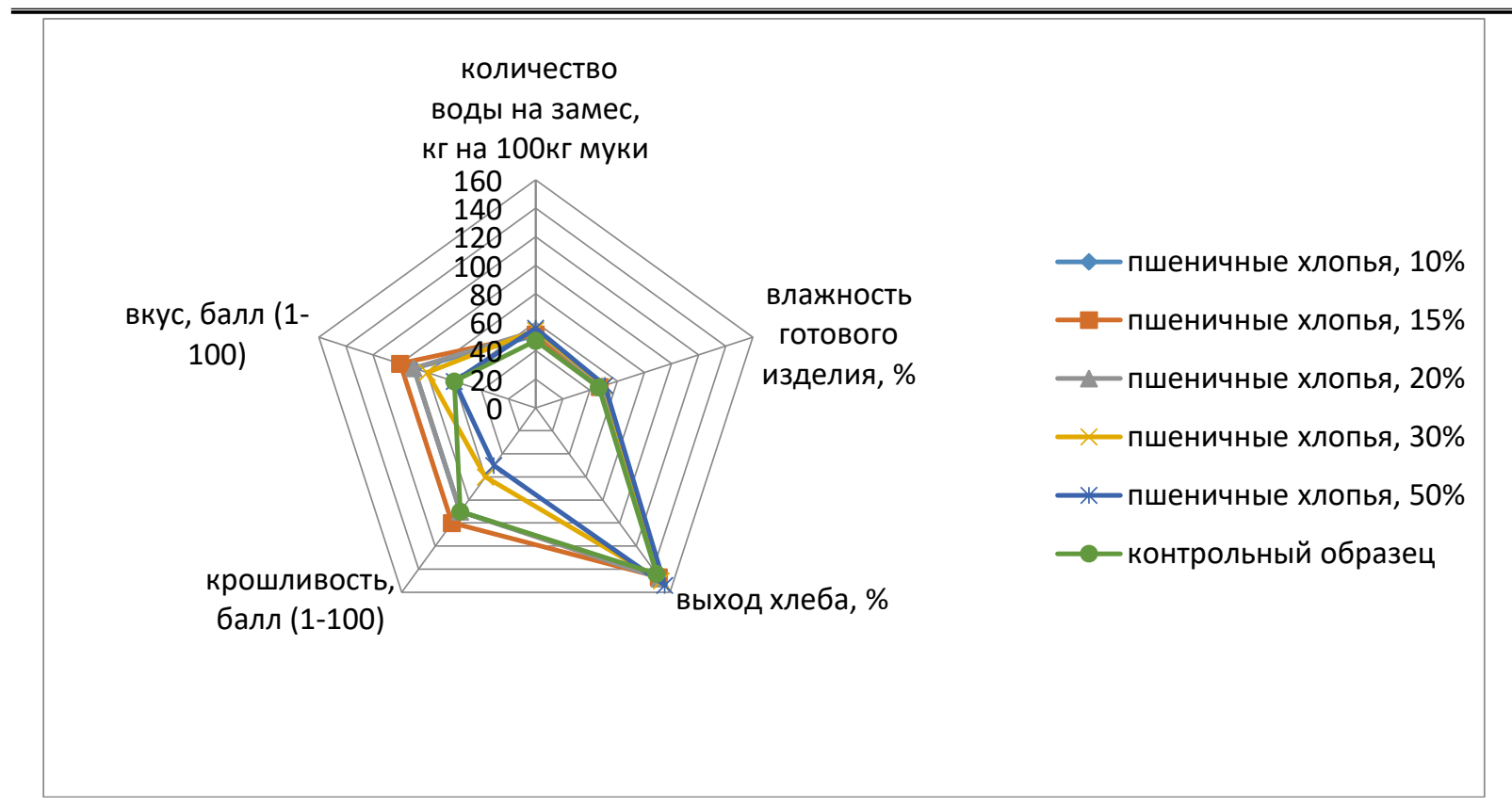

Puc. 3. Влияние дозировки пшеничных хлопьев на качество хлеба

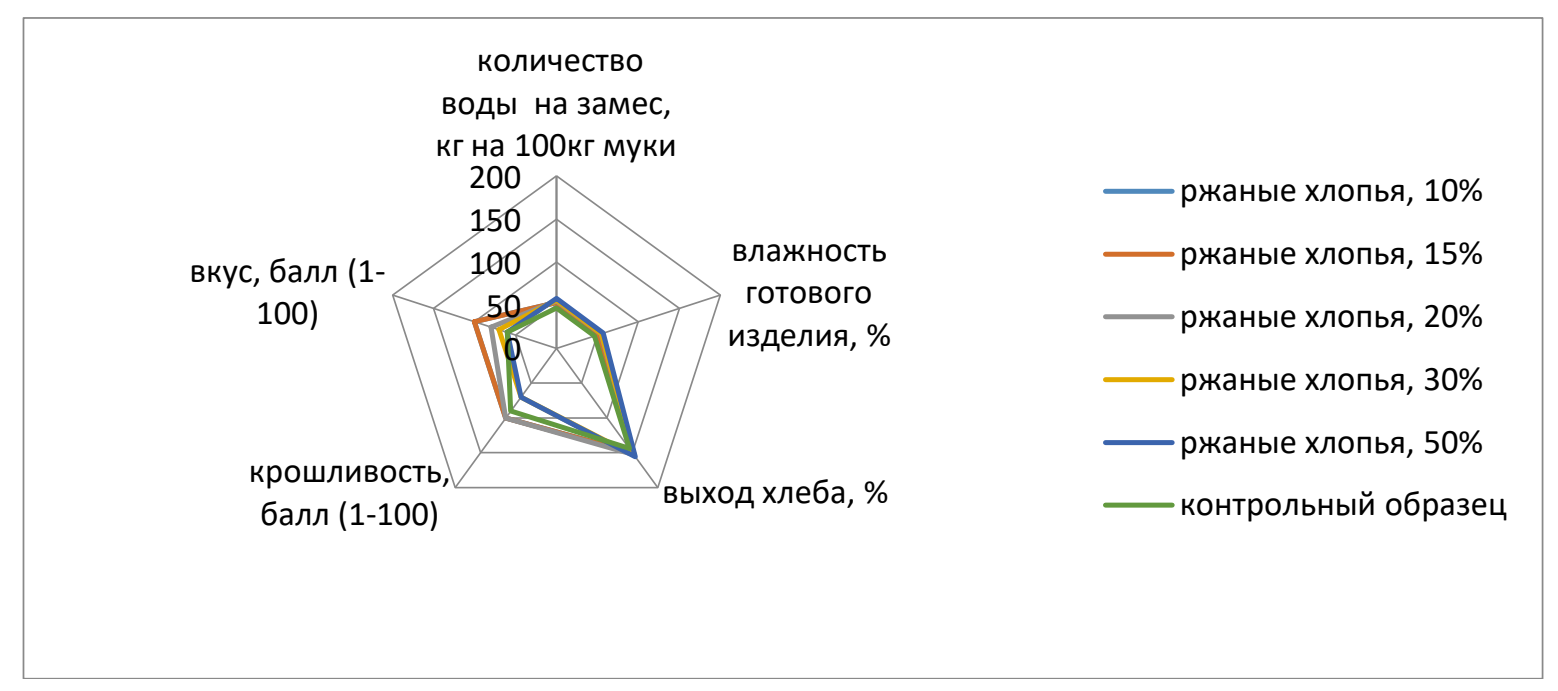

Puc. 4. Влияние дозировки ржаных хлопьев на качество хлеба

Рисунки 2-4 демонстрируют изменение показателей качества хлеба с различной дозировкой хлопьев. На диаграммах видно, что при незначительных различиях влажности и выхода хлеба органолептические показатели изделий с 15$20 \%$ хлопьев в рецептурах получили наивысшие оценки. Изделия с $10 \%$ дозировкой хлопьев имеют недостаточно выраженные вкус и аромат, а дозировка 30 \% и более хлопьев значительно уплотняет мякиш и увеличивает крошливость изделий.
Из приведенных данных установлено, что наиболее рациональным количеством хлопьев в производстве хлеба является 15 \%-я дозировка.

B процессе изучения влияния злаковых хлопьев на качество хлебобулочных изделий определены основные этапы технологии производства хлеба. Современное хлебопекарное производство в настоящее время использует технологию замачивания цельного зерна не менее чем на 12 часов с периодическим промыванием и предусматривает последующее его диспергирование. Использование злаковых хлопьев в производстве хлеба и хлебобулочных изделий 
имеет существенное отличие. Предложенная технология не предусматривает длительных процессов подготовки зерна, а именно - замачивание, промывание, диспергирование. Замоченные хлопья вводятся непосредственно при замесе теста. Далее технологический процесс протекает по стандартным схемам.

Экономические расчеты также подтверждают целесообразность дозировки зернового сырья в пределах 10-20\%. Повышение дозировки выше $20 \%$ ведет к удорожанию продукта. а снижение содержания хлопьев менее $10 \%$ не приносит функциональных изменений в качество хлебобулочных изделий. Внесение в рецептуру хлопьев менее $10 \%$ не приводит к ощутимому увеличению пищевых волокон в составе изделий. При внесении $10 \%$ хлопьев в рецептуру расчетное количество пищевых волокон возрас- тает менее чем на 0,2-0,6 \%. Также внесение менее $10 \%$ злаковых хлопьев практически не влияет на вкусовые характеристики и выход хлебобулочных изделий. Выход хлеба при внесении менее $10 \%$ хлопьев возрастает не более чем на $1,5 \%$.

Для внедрения в производство рекомендуется следующее соотношение компонентов в рецептуре хлеба:

Мука пшеничная хлебопекарная первого сорта $-85,0$ кг.

Хлопья злаковые (овсяные, пшеничные или ржаные) - 15,0 кг.

Соль поваренная $-2,0$ кг.

Дрожжи прессованные - 1,0 кг.

Влажность мякиша - 48-52 \%.

Расчеты сырьевой себестоимости приведены в таблице.

\section{Сырьевая себестоимость хлеба с использованием злаковых хлопьев}

\begin{tabular}{|c|c|}
\hline $\begin{array}{c}\text { Количество злаковых хлопьев } \\
\text { в рецептуре хлеба, \% }\end{array}$ & Сырьевая себестоимость готового хлеба, руб/кг \\
\hline Контрольный образец & 13,80 \\
\hline 10 & 14,90 \\
\hline 15 & 14,95 \\
\hline 20 & 15,50 \\
\hline 30 & 16,53 \\
\hline 50 & 18,67 \\
\hline
\end{tabular}

Из приведенных данных установлено, что при введении $10 \%$ хлопьев сырьевая себестоимость готового хлеба возрастает на $8 \%$, а показатели качества для потребителя изменяются незначительно. Введение хлопьев в количестве $15 \%$ дает ощутимый результат в качественных показателях, при этом разница в себестоимости между 10 и $15 \%$ внесением хлопьев незначительна. Кроме прямых экономических расчетов необходимо учитывать особенности технологического процесса, не требующие установки дополнительного оборудования и использования дополнительных производственных площадей.

Выводы. Проведенные исследования показали целесообразность и экономическую эффективность применения плющеного зерна или злаковых хлопьев из зерна овса, пшеницы и ржи при производстве хлеба.
Основным преимуществом применения зерновых хлопьев в производстве хлеба является простота их подготовки к производству и хорошая набухаемость. Влагоудерживающая способность зерновых хлопьев варьируется от 87 до $97 \%$, что создает благоприятные условия для увеличения выхода хлеба по сравнению с контрольными образцами на 5-7 \%. В результате проведенных исследований установлено оптимальное количество злаковых хлопьев в рецептурах 15-20 \% по отношению к муке.

Применение крупяных хлопьев не требует длительного процесса замачивания и дополнительного нагрева. Достаточно 3 часов набухания в условиях производственных цехов при температуре не выше $25^{\circ} \mathrm{C}$.

Экономическая целесообразность применения хлопьев в хлебопечении обуславливается их доступностью, простотой подготовки. Технологический процесс подготовки хлопьев к про- 
изводству не предусматривает установки дополнительного оборудования и производственных площадей.

\section{Литература}

1. Онищенко Г.Г. Концепция развития функционального и специализированного хлебопечения в Российской Федерации до 2020 года (хлеб - это здоровье). - М., 2013. $-29 \mathrm{c}$.

2. Васькина В.А., Касьянова Л.А, Кавелик Р.Н. Производство новых продуктов профилактического питания // Экология человека: проблемы и состояние лечебно-профилактического питания: сб. докл. III Междунар. симп. - М., 1994. - С. 91-92.

3. Типсина Н.Н., Туманова А.Е. Разработка новых видов печенья функционального назначения / Краснояр. гос. аграр. ун-т. Красноярск, 2019. - 163 с.
4. Николаев Б.А. Расчет и контроль выходов хлебных изделий. - М.: Пищепромиздат, 1953. $-88 \mathrm{c}$.

\section{Literatura}

1. Onishhenko G.G. Koncepcija razvitija funkcional'nogo i specializirovannogo hlebopechenija v Rossijskoj Federacii do 2020 goda (hleb jeto zdorov'e). - M., 2013. $-29 \mathrm{~s}$.

2. Vas'kina V.A., Kas'janova L.A, Kavelik R.N. Proizvodstvo novyh produktov profilakticheskogo pitanija // Jekologija cheloveka: problemy i sostojanie lechebno-profilakticheskogo pitanija: sb. dokl. III Mezhdunar. simp. - M., 1994. - S. 91-92.

3. Tipsina N.N., Tumanova A.E. Razrabotka novyh vidov pechen'ja funkcional'nogo naznachenija / Krasnojar. gos. agrar. un-t. Krasnojarsk, 2019. - $163 \mathrm{~s}$.

4. Nikolaev B.A. Raschet i kontrol' vyhodov hlebnyh izdelij. - M.: Pishhepromizdat, 1953. $88 \mathrm{~s}$. 